\title{
Cidades e cidadãos imaginados pelos meios de comunicação
}

\begin{tabular}{c} 
Néstor García Canclini \\
Universidad Autônoma Metropolitana, Iztapalapa - México \\
\hline \hline
\end{tabular}

\section{Resumo}

A megalópole Cidade do México existe como espaço social e físico, ordem e desordem demográfica, mas também nas formas imaginadas todos os dias pela imprensa, o rádio e a televisão. Estas mídias organizam comunidades invisíveis de audiências que se informam através delas sobre a cidade e, às vezes, participam por meio de cartas ou telefonemas. De que forma a esfera pública é reconstituída nesses circuitos comunicacionais? Esses meios contribuem para a transparência e a democratização da cidade ou simplesmente reproduzem o senso comum urbano?

Palavras-chave: meios de comunicação, imprensa, estudos urbanos, México

\begin{abstract}
The Mexico City megalopolis exists as a social and physical space, as a demographic ordering and disorder, but also in the forms imagined every day by the press, radio and television. These media organize the invisible communities of their public, which are informed through the media about the city, and they sometimes participate with reader's letters or in phone-in programs. How is the public sphere reconstituted in these communicational circuits? Do the media contribute to the transparency and democratization of the city, or do they simply reproduce urban common sense?
\end{abstract}

Key words: media, press, urban studies, Mexico 
Uma das novidades dos estudos urbanos e de comunicação é a tendência em entender a cidade em relação aos processos de comunicação e a vinculação destes à trama urbana. A cidade já não é mais vista como um mero cenário para a habitação e o trabalho, ou seja, como simples organização espacial, lugar de assentamento da indústria e dos serviços. Por outro lado, os meios de comunicação não são concebidos unicamente como redes invisíveis e deslocalizadas, cuja dinâmica poderia ser entendida somente através das estratégias empresariais e dos recursos tecnológicos mobilizados.

Na segunda metade do século XX, quando a concentração demográfica e a expansão territorial das megacidades debilitam a conexão entre suas partes e, ao mesmo tempo, as redes comunicacionais levam a informação e o entretenimento aos domicílios, os usos das cidades são reorganizados: a desordenada explosão rumo às periferias, que faz com que os habitantes percam o sentido dos limites de "seu" território, é equilibrada com os relatos dos meios de comunicação sobre o que acontece nos lugares mais distantes dentro da cidade. Do passeio do flâneur que reunia informações sobre a cidade para depois transferi-las às crônicas literárias e jornalísticas, passamos, em cinqüenta anos, ao helicóptero que sobrevoa a cidade e oferece a cada manhã, através da tela do televisor e das vozes do rádio, o panorama de uma megalópole vista em conjunto, sua unidade recomposta por quem vigia e nos informa. Os desequilíbrios e incertezas engendrados pela urbanização que desurbaniza, por sua expansão irracional e especulativa, parecem ser recompensados pela eficiência tecnológica das redes de comunicação. A caracterização sócio-demográfica do espaço urbano não consegue dar conta de seus novos significados se não incluir também a recomposição que a ação midiática Ihes imprime.

Por sua vez, o rádio, a televisão e todo o pacote telemático, comprometidos com a tarefa de descrever e narrar a cidade, redesenham suas estratégias comunicacionais para estabelecerem-se em espaços concretos e mais ou menos delimitados. Por mais transnacionais que sejam seus investimentos, a estrutura da empresa e a composição de seu público, assume-se que suas audiências esperem que Ihes seja dito o que significa estar juntos. Certamente, estes meios devem cumprir o papel de contato com o que acontece em lugares distantes neste planeta globalizado. Contudo, como as cidades também se globalizam - isto é, tornam-se cenários de gestão do que ocorre nas finanças e na política, nas guerras e nos rituais diplomáticos, nos espetáculos de arte e nas religiões do mundo todo praticamente - não é difícil sincronizar as vocações locais e globais das cidades e dos meios de comunicação.

A cidade converte-se em metáfora da sociedade da informação e da comunicação: "transformação dos lugares em espaço de fluxos e canais", segundo a formulação de Manuel Castells (1983). Ou, ainda, como afirma Mabel Piccini 
(1996), "a cidade se fragmenta em inúmeros pontos sustentados apenas por traços viários que conferem à paisagem uma idéia de continuidade e movimento, de modo que o espaço urbano parece transformar-se em um lugar de trânsito e de passagem entre um lugar e outro [...] trata-se de chegar e não de deter-se; de circular e não de vagar ou perambular". Por isso, aludindo às políticas que atualmente se ocupam e desinteressam pelas cidades latino-americanas, Jesús Martín Barbero afirmou que a maior preocupação dos urbanistas e funcionários não é tanto com o caos urbano e seus efeitos sobre a contaminação e a perda de qualidade de vida, mas sim com que as pessoas possam continuar se movendo: "Que circulem! Isso justificará o fim das praças, as obras para endireitar becos, ampliar e interligar as avenidas. $O$ que se perder nesse processo, será lucro do ponto de vista do fluxo" (Martín Barbero, 1994:25).

Mesmo onde não foram destruídos os centros históricos, as praças, os lugares que mantinham viva a memória e permitiam o encontro das pessoas, sua força diminui frente à remodelação dos imaginários operada pelos meios de comunicação. Os relatos mais influentes sobre o que significa a cidade emergem agora da imprensa, do rádio e da televisão. No tumulto heterogêneo e disperso de signos de identificação e referência, os meios não propõem tanto uma nova ordem, mas sim oferecem um espetáculo reconfortante. Mais do que estabelecer novos lugares de pertencimento e de identificação de raízes, o importante para as mídias é oferecer certa intensidade de experiências. Em vez de oferecer informações que orientem o indivíduo na crescente complexidade de interações e conflitos urbanos, os meios de comunicação ajudam a imaginar uma sociabilidade que relaciona as comunidades virtuais de consumidores midiáticos: os jovens com outros jovens; as mulheres com suas iguais; os que se interessam por algum esporte com outros praticantes em diferentes lugares da mesma cidade e do mundo; os gordos com os gordos; os que gostam de salsa ou bolero ou rock com outros que têm as mesmas preferências. As comunidades organizadas pela mídia substituiriam então os encontros nas praças, os estádios ou os salões de baile pelos não-lugares das redes audiovisuais.

Boa parte dos estudos que estão repensando as articulações entre cidade e comunicação, opõe a integração espacial da sociabilidade bairrista-urbana à disseminação desterritorializada das mídias. Esta tendência está presente mesmo nas análises mais sutis, como as citadas. Eu mesmo concebi nestes termos a descontinuidade e, em certo modo, a substituição de uma sociabilidade por outra (García Canclini, 1993).

No entanto, a pesquisa sobre a Cidade do México que desenvolvemos nos últimos anos no Programa de Estudos sobre Cultura Urbana da Universidade Autônoma Metropolitana, permitiu a reformulação desta perspectiva. Partimos da questão de como são constituídos hoje os imaginários em uma megacidade. Por 
outro lado, também nos perguntamos sobre como se configuravam no passado. Uma parte do estudo, publicado recentemente em um livro, referiu-se aos modos pelos quais a fotografia participou nessa construção de imaginários ao registrar as viagens pela cidade desde os anos quarenta até a atualidade (García CancliniCastellanos-Rosas Mantecón, 1996). O trabalho de Ana Rosas Mantecón (1996) mostra de que maneira o discurso do cinema assumiu o crescimento massivo da cidade devido às migrações. A principal maneira de tratar os "estranhos" foi construindo estereótipos. Os novos moradores chegados da província mexicana são sempre os ingênuos com ilusões de prosperar, cujo arcaísmo os impede de localizar-se nos códigos urbanos e, por isso, fracassam, são enganados, perdem sua pureza, até que, por fim, muitos retornam ao seu lugar de origem de onde nunca deveriam ter saído. No entanto, como a maioria permanece na capital, o estereótipo do imigrante incapaz de adaptar-se à vida urbana, acentuando os males das grandes cidades, coincide com a culpabilidade discriminadora em relação à imigração identificada no discurso de grupos entrevistados a quem mostramos fotos e fragmentos de filmes (ver o livro citado).

A ficção do cinema mostrou-se pouco flexível para perceber e transmitir a complexa multiculturalidade da Cidade do México. Veremos agora se os meios de comunicação de massa tiveram disposição para elaborar imagens mais "realistas" que captam com maior sutileza a problemática da capital. Para tanto, considerarei especialmente aos trabalhos de Aguilar (1996), Winocur (1996) e Vernik (1996) referentes ao papel da imprensa, do rádio e da televisão no desenvolvimento dos imaginários urbanos.

\section{Onde são fundadas as cidades}

"No alto de um monte, para defender-se; no litoral, para partir; ou, como costumam descrever os mitos, às margens dos rios, para encontrar um eixo de orientação para o próprio grupo [...] Contudo, as cidades também são fundadas dentro dos livros". É desta maneira que Rosalba Campra responde à pergunta, em um texto que recorda as fundações de Paris nos escritos de Balzac e Proust, a Buenos Aires de Borges e do tango, a Praga de Kafka, a Roma de Pasolini e o México de Carlos Fuentes. Fala também das cidades erguidas como invenções soberbas e livres: Santa Maria, de Onetti; Macondo, de García Márquez e as cidades invisíveis de Calvino (Campra, 1994:19-21).

Segundo Campra, uma característica comum a essas cidades, reais ou imaginárias, é o fato de serem definidas em relação aos limites, como universos diferenciados frente à indeterminação da natureza. Mesmo quando as fronteiras não possuem a nitidez das muralhas, os textos que as fundam as imaginam distinguindo claramente o interior do exterior, o que está dentro e o que está fora. 
Em compensação, as cidades da era da vídeo-cultura ou do ciberespaço são situadas em um âmbito incomensurável, em um conjunto de redes e fluxos existentes tanto no mundo físico como no mental. Diferentemente da cidade delimitada, "fornecedora de identidade, proteção e sentido" (ib.:39), cabe perguntar como são formadas agora as identidades nessas urbes que não se opõem à natureza nem a outras cidades tão rigidamente como no passado.

De que maneira são fundadas e imaginadas as cidades quando, mais que a literatura, os discursos da imprensa, do rádio e da televisão passam a cumprir esse papel? Estes são os principais agentes construtores do sentido urbano, os que selecionam e combinam as referências emblemáticas. São eles também que fazem com que alguns cidadãos participem do debate sobre o que a cidade é ou poderia ser e depois propõem aos demais suas opiniões e demandas como síntese imaginária do sentido da cidade e do que significa ser cidadão.

\section{O jornal}

A imprensa jornalística foi o primeiro recurso tecnológico moderno para informar-se sobre a cidade. Sua aparição foi decisiva para a instauração da noção moderna de esfera pública, e este meio continua oferecendo mais oportunidades que os demais para a elaboração do debate sobre os assuntos públicos. A dispersão da imprensa em uma grande cidade - são publicados diariamente 25 jornais na Cidade do México - já oferece uma primeira idéia da variedade de atores que intervêem nessa disputa, a partir de diferentes interesses e posições. A esta diversidade de enunciadores é necessário somar ainda a multiplicidade de vozes internas (jornalistas, publicidade, editores com posições diferentes), nacionais e internacionais (agências, correspondentes) existentes em um jornal. Esta diversidade costuma ser maior e sofrer menos censura na imprensa que nos outros meios de massa.

Embora a maioria dos jornais tenha uma relação preferencial com a cidade em que são produzidos, o conjunto de sua informação mostra uma articulação complexa entre o local, o nacional e o internacional. Revela diariamente que a vida pública tem raízes na cidade, no entanto, essa esfera micro, para usar as expressões de John Keane, entrelaça-se com o mesopúblico (os milhões de pessoas que interagem no contexto do Estado-nação) e com o macropúblico (os circuitos de alcance supranacional e ainda global, representados pelas agências transnacionais de notícias, as empresas produtoras de filmes e programas de televisão).

As notícias sobre a Cidade do México ocupam 3,7\% do total das informações presentes nos jornais desta cidade. Este dado foi divulgado por Miguel Ángel Aguilar em estudo realizado entre outubro e dezembro de 1992, (Aguilar, 1996). Mesmo levando em consideração que nem todos os jornais concedem a 
mesma importância aos fatos ocorridos na cidade, o contraste entre o total de informações da urbe com os $18 \%$ ocupados pelas notícias internacionais mostra a relativização do entorno imediato por parte da imprensa.

Quem fala sobre a cidade nos jornais? Predominam as fontes e os atores "oficiais", com 43\% das referências. Em segundo lugar, os porta-vozes da sociedade civil, com $28 \%$, depois as instâncias de representação, partidos, políticos, etc, com $17 \%$. Já a própria distribuição dos enunciadores revela a predominância do Estado, semelhante ao que tem ocorrido no México ao longo do século XX, e que, como podemos constatar, estende-se também aos meios que se apresentam como independentes.

No que diz respeito às notícias urbanas priorizadas pelos jornais, destacam. se as relacionadas ao meio ambiente e ecologia, com um quarto do total de referências. Em seguida, estão as relativas aos serviços urbanos, redes e equipamentos, com 22\%, depois segurança e violência, com 22\%; Estes dados foram apurados em $60 \%$ dos jornais na Cidade do México. Uma porcentagem menor de notícias é dedicada aos distritos do Distrito Federal, e pouquíssimas notícias fazem alusão aos municípios conurbados, onde reside atualmente mais da metade da população da área metropolitana. Também quanto às fotografias publicadas pelos jornais, $49 \%$ correspondem ao Distrito Federal enquanto que a periferia recebe apenas $17 \%$.

A imprensa contribui para a imagem de uma cidade massiva, cujas particularidades se concentram no centro histórico ou em outras regiões centrais. Às vezes, os jornais publicam informações sobre lugares pouco conhecidos, mas com maior freqüência, principalmente em fotografias, mostram cenários facilmente identificáveis, que tendem a reproduzir saberes convencionais. Estamos, portanto, diante de um meio que oferece mais elementos discursivos que outros para refletir sobre a cidade e elaborar a condição de cidadão, mas que não contribui para expandir a visão sobre a cidade em uma proporção comparável ao crescimento de seu território e sua complexidade. A despeito da ênfase sobre a novidade e, em alguns jornais, sobre o insólito, a maioria termina por concentrar-se no conhecido. Embora se descrevam como informadores de fatos atuais e, portanto, como meios que privilegiam o presente, a maioria dos jornais insiste no já habitual, prolongando estereótipos formados historicamente. Os relatos diários mudam, mas as estruturas argumentativas que os sustentam, como afirma Aguilar, demonstram "estabilidade e fixidez".

Se esta fidelidade ao estabelecido se relaciona com o predomínio das vozes oficiais, é possível concluir que a imprensa tende a imaginar os cidadãos em um lugar subordinado que reproduz a ordem. Mesmo apresentando um registro da pluralidade social e dos protestos mais profusos que o rádio e a televisão, os jornais acabam concebendo a cidade como um espaço muito mais homogêneo do 
que realmente é, e a vida pública mais como gestão e administração que como lugar de inovações e mudanças. A ação cidadã, que pode chegar a ser pública desde que difundida pelos meios, fica relegada a um discurso "periférico ao estatal".

Para refinar estas teses, extraídas da análise global dos jornais na Cidade do México, seria necessário distinguir os estilos comunicacionais segundo as orientações ideológicas de cada jornal e, evidentemente, como se relacionam com eles diferentes leitores. No entanto, sabemos que os cidadãos definem suas preferências de leitura por sua afinidade com as tendências do jornal, o que reforçaria o papel reprodutor identificado em seu discurso. Parece verossímil, portanto, afirmar que a comunidade virtual dos leitores da imprensa não se configura como radicalmente distinta, menos ainda substitutiva, do sentido urbano construído pelas experiências bairristas e por outras formas de participação que proporcionam imagens "diretas" do que é a cidade.

\section{O rádio}

Desde as primeiras décadas deste século, este meio falou sobre as cidades, as representou e foi muito útil para que os imigrantes recém chegados conhecessem os usos lingüísticos, as notícias, a publicidade e as diferentes formas de expressar os sentimentos na vida urbana. Sem o rádio, escreveram Carlos Monsiváis e Jesús Martín Barbero, não teria sido possível a formação de nações capazes de integrar modos de falar de diferentes regiões, nem teriam tido sucesso líderes populistas que souberam usá-lo para comunicar-se com todas as classes sociais.

Porém, nas últimas décadas, o rádio tornou-se também um palco para a expressão cidadã. Os programas que recebem "gente comum" ou abrem as linhas de telefone da emissora aos ouvintes servem de fórum mesmo para aqueles que não se interessam em participar de partidos políticos ou movimentos sociais, querem manifestar suas opiniões. Centenas de ligações buscam diariamente amplificar reclamações, pedir a solidariedade dos próprios locutores ou, ainda, de outros ouvintes. Como se perguntam Ángela Giglia e Rosalía Winocur (1996) estes programas tendem a tornar-se "uma ponte entre a autoridade e os cidadãos ou, na verdade, apenas fabricam soluções simbólicas dentro da mesma lógica de construção do acontecimento midiático?"

Segundo as autoras, quando o circuito radiofônico se abre não só para funcionários públicos e especialistas, aumenta sua confiança entre os ouvintes, estes sentem que é possível comunicar-se com seus pares e usar "a linguagem corrente sem formalismos". Pode tratar-se de uma denúncia ou simplesmente de 
manifestar uma opinião, ser ouvido ou assumir algum tipo de protagonismo: os comentários obtidos por Giglia e Winocur mostram que as intervenções nos programas têm diversas motivações e não compõem um único sentido final. Não se pode simplesmente afirmar que este modo amplia a participação cidadã nos assuntos públicos.

Além disso, os condutores de tais programas traduzem as declarações dos ouvintes para integrá-las em um discurso homogêneo, embora as diferentes maneiras de inter-relação invocadas por eles pareçam reconhecer a variedade de posições sócio-urbanas a partir das quais se fala: "Você que transita pelo viaduto Tlalpan", "senhor ou senhora", "o público", "os habitantes", "um amigo do auditório". Nos casos em que há telefone aberto aos ouvintes, admitem-se expressões literais dos participantes e, em alguns casos, são selecionadas e reelaboradas para adequá-las aos objetivos da emissora. Em todos os casos, no entanto, as tendências habituais são reduzir a complexidade o máximo possível e situar as opiniões diversas em um consenso imaginado como compartilhado pela maioria. Para este "senso comum" a cidade se caracteriza pela insegurança generalizada, o "despreparo" do corpo policial, "os valores do povo" e, principalmente, pela capacidade do rádio de permitir a expressão de todos.

Essas autoras consideram que a valorização de tais espaços participativos deve ser feita levando em consideração uma certa negociação entre locutores e receptores. O rádio propicia a expressão de seus ouvintes em troca do reconhecimento de sua credibilidade. Permite que a "cidadania" fale, mas esta deve deixar-se limitar, orientar e, até mesmo, censurar. No fim das contas, resta a dúvida de quanto o rádio concede para que se estenda a esfera pública, e o quanto procura através da idéia de "livre expressão" testemunhos que legitimem seu lugar no mercado das comunicações.

A seleção das queixas urbanas, seu alinhamento em consensos previamente constituídos e a afirmação de "valores sagrados do povo" demonstram o papel reprodutor da ordem social exercido também por este meio. As freqüentes referências dos "ouvintes que falam" a instituições que não funcionam, funcionários que não atendem a seus pedidos ou somente os atendem mediante alguma forma de corrupção, expõem o rádio, bem como a imprensa e a televisão, como substitutos dos procedimentos "normais" de representação e consideração do interesse público.

As conclusões desta pesquisa sobre a participação radiofônica coincidem com as de outros estudos semelhantes. Os meios constroem seus espectadores e, na medida em que pretendem desempenhar o papel de esfera pública, configuram modos simbólicos, midiáticos de ser cidadãos. Como afirma Beatriz Sarlo a respeito da televisão: 
“... ante à opacidade crescente de outras instituições, ante à complexidade infernal dos problemas públicos, a televisão apresenta o que acontece tal como está acontecendo e, em seu cenário, as coisas parecem mais verdadeiras e simples. Investida de uma autoridade que nem a igreja, os partidos e a escola têm, a televisão ecoa a voz de uma verdade que todo mundo pode entender rapidamente. A epistemologia televisiva é, neste sentido, tão realista quanto populista tem submetido a uma demolidora crítica prática todos os paradigmas de transmissão do saber conhecidos na cultura letrada" (Sarlo, 1994:80-81).

\section{A televisão}

Este meio é, em certo sentido, reflexo do que ocorreu com a Cidade do México e com outras megalópoles. Nas mesmas décadas, desde os anos cinqüenta até hoje, em que o crescimento da mancha urbana se acelerou e sua disseminação caótica suprimiu a possibilidade de imaginá-la como um conjunto, a televisão se expandiu para $95 \%$ dos lares. Os filmes ou shows que deixamos de ver porque são apresentados a uma ou duas horas da nossa casa chegam à tela da TV ou podem ser substituídos por entretenimentos eletrônicos domésticos. O que é possível saber e imaginar sobre a megacidade não nos chega tanto pelas limitadas experiências diretas que temos ao viajar por ela, mas sim pelas notícias e reflexões que o olhar "onisciente" da televisão instala nos lares. Com o auxílio de helicópteros que percorrem a urbe, com câmeras "no lugar dos fatos", com convidados que os viveram diretamente, constrói visões verossímeis que simulam recompor o sentido global da vida cidadã.

De que maneira o recompõem? Esteban Vernik (1996) e Armando Silva (1996) oferecem versões distintas e complementares das estratégias televisivas.

O estudo de Vernik sobre a apropriação das notícias televisivas em duas "comunidades" localizadas na periferia da Cidade do México, no velho povoado de San Pedro Mártir, é esclarecedor sobre como diferentes setores vinculam as notícias televisivas à sua vida cotidiana. Ao projetar um vídeo com fragmentos de notícias televisivas (imagens do trânsito, a poluição, manifestações de rua e um grande incêndio) houve distintas reações em um dos grupos, formado por habitantes de classe média que vivem em um condomínio fechado construído recentemente, e em um segundo grupo composto por moradores antigos, de classe baixa.

A notícia do incêndio suscitou pouco interesse no primeiro grupo, mas teve grande ressonância na "comunidade" popular. Vernik interpreta esta diferença relacionando-a com o temor e a vulnerabilidade que os setores mais baixos experimentam diariamente na vida urbana. Ao questionar se haviam ocorrido 
incêndios na região em que vivem, vários dos entrevistados deste setor recordaram que já haviam sido salvos, ou já haviam ajudado a salvar alguns vizinhos de um incêndio provocado por depósitos ou indústrias localizadas em lugares impróprios. O caso extremo, que o autor toma como sintomático, é o de uma mulher de San Pedro Mártir que teria visto no noticiário matutino de televisão imagens de um incêndio no centro da cidade, no quarteirão onde fica a casa de sua irmã. Ela acompanhou durante três horas em tempo real como o incidente se desenrolava e, por fim, era controlado. Esta mulher não tinha telefone para comunicar-se com sua irmã, e a única vizinha que poderia emprestar-Ihe o telefone tinha ido trabalhar.

Por outro lado, os habitantes do condomínio, apesar de terem habitações idênticas e status sócio-econômico semelhantes, não se comportaram como comunidade no sentido de compartilhar relações emocionais, laços de "socialização", segundo a fórmula de Simmel. Seus vínculos estavam limitados à "manutenção instrumental do condomínio": funcionamento dos serviços e da segurança. Constroem sua "sociabilidade" e seus contextos afetivos em outras partes da cidade, em seus trabalhos e em outras relações escolhidas mais livremente, ou seja, não condicionadas pela residência em um determinado território. Frente a uma emergência, como um incêndio, dispõem de telefone, carros e formas rápidas de contato.

A comunicação midiática tem significados e repercussões diferentes em grupos de distinta localização econômica e sócio-cultural. Mesmo habitando um mesmo bairro, a informação é recebida de diferentes maneiras conforme os recursos de modernidade dos quais se dispõe, tais como telefone e automóveis, enfim, segundo a possibilidade de vincular-se não só com o território residencial, mas também com outras regiões da cidade. A recepção angustiada da notícia do incêndio em uma família popular sugere, segundo Vernik, que a tela da TV é "o lugar que a modernidade mass-midiática reserva aos excluídos".

Em outras situações, as mais freqüentes, quando os espectadores não encontram na televisão um drama familiar como os descritos por Vernik, a exibição de tragédias sociais ou violências cotidianas torna a vida urbana um espetáculo distante. As notícias, conforme explica Armando Silva, "são para um público distante do local dos acontecimentos". Os incestos e as disputas "curiosas" narrados pelo show da Cristina ou por um noticiário, nos dois casos por "testemunhas verdadeiras" (mesmo quando são atores contratados), a perseguição de O.J. Simpson e o julgamento de um traficante, enfim, todos esses fatos são incorporados como parte de uma realidade digerível, aceitável na medida em que é oferecida como um espetáculo distante. Não altera nossa rotina diária conquanto não tem as pretensões "realistas" de uma representação fotográfica, nem as propriedades estéticas de um relato literário, nem a força causal de uma explicação 
histórica. Trata-se, ainda segundo Silva, de relatos "virtuais midiáticos" que servem para fantasiar, fantasias que servem, por sua vez, para "desrealizar". Deste modo, a televisão prende fantasias cidadãs que poderiam levar "a mudanças sociais inesperadas".

\section{Midiatização de massa $=$ Mimetismo de massa?}

A tão referida ação transformadora das indústrias culturais deve ser redimensionada e requalificada à luz destes estudos que problematizam, com uma nova perspectiva, as funções dos meios de comunicação. Uma descoberta que se confirma em diversas pesquisas dos últimos anos é que a imprensa, o rádio e a televisão contribuem para reproduzir, mais do que para alterar, a ordem social. Seus discursos têm uma função de mimese, de cumplicidade com as estruturas sócio-econômicas e com os lugares comuns da cultura política. Mesmo quando registram manifestações de protesto e testemunham a desigualdade, editam as vozes dissidentes ou excluídas de maneira a preservar o status quo.

As cidades são imaginadas pelos meios de comunicação como lugares onde as transformações acabam sendo absorvidas pela normalidade, e tudo que ultrapassa ou rompe a ordem urbana é reconstituído, em última instância, pelas sínteses informativas midiáticas. Os cidadãos são imaginados como clientes, como legitimadores da "veracidade" construída pelos meios de comunicação, como interlocutores necessários para justificar esta "veracidade" ante os poderes (econômicos, políticos), que também são clientes enquanto anunciantes e sócios na reprodução da ordem.

De qualquer forma, não devemos subestimar o que foi conquistado em termos de transparência e democratização social graças ao desenvolvimento da comunicação de massa. É difícil imaginar que as exigências democratizadoras nas cidades, os protestos devido à poluição e violação dos direitos humanos, teriam podido alcançar a transcendência que obtiveram na segunda metade do século XX sem a repercussão garantida pela imprensa, rádio e TV. As seções especiais sobre a "cidade" ou a "metrópole", os cadernos sobre temas urbanos criados por alguns jornais nos últimos anos expressam a preocupação de uma parte da cidadania com relação ao crescimento sem planificação e os efeitos autodestrutivos do nosso modo de habitar as cidades. Certamente, são impróprias as afirmações generalizadas que atribuem indiscriminadamente ao conjunto das indústrias culturais a virtude de ter ampliado o horizonte informativo das massas. No entanto, se fizermos uma distinção entre os meios mais comercializados, mais dependentes dos índices de audiência e, portanto, meros reprodutores dos gostos e senso comum majoritários, e, por outro lado, aqueles que se preocupam em 
difundir a informação e representar as vozes críticas, deveremos reconhecer que estes últimos conseguiram enriquecer as pautas de discussão nas sociedades contemporâneas.

Porém, quantas destas revelações e ampliações da pauta se acumulam, se convertem em memória e vontade de transformação? Não há nada mais anacrônico que as notícias do jornal de ontem, já se disse muitas vezes. Mais vertiginoso ainda é o regime de obsolescência visual da televisão: com a multiplicação atual de canais exacerba-se a necessidade de neutralizar o zapping mediante a renovação incessante de estímulos. Empurram-nos inexoravelmente as tecnologias audiovisuais ao recanto doméstico, ao esquecimento e à espectacularização a distância do público, ou existem formas de reapropriação crítica das representações midiáticas?

Mabel Piccini (1996), argumenta que os meios audiovisuais, devido a sua "sintaxe rotineira", sua exaltação do efêmero e sua complacência com o próximo e o familiar, favorecem a ancoragem em saberes consagrados e em resíduos de ideologias misturados a "um tipo de seletividade pouco reflexiva". Que capacidade de seleção pode haver em "culturas da privação", cujo empobrecimento material e simbólico é agravado pelas políticas econômicas e comunicacionais atuais, para as quais não há outro remédio senão preferir "o existente ao nada ou ao vazio"?

A visão desta autora, sustentada por uma pesquisa etnográfica sobre a reação à televisão na Cidade do México, muito mais densa do que foi possível incluir neste artigo, converge com um dos livros mais incisivos que a sociologia latino-americana já produziu sobre os meios de comunicação. Refiro-me ao volume escrito por José Joaquín Brunner e Carlos Catalán, Televisión, libertad, mercado y moral, resultado de seus estudos sobre o consumo cultural e do período em que dirigiram o Conselho Nacional de Televisão no Chile. Cabe esclarecer que o exame destes autores difere do de Piccini e outros analistas, como Beatriz Sarlo, pois Brunner e Catalán valorizam positivamente o fato de a televisão ter rompido "definitivamente o equilíbrio histórico de subordinação dos elementos da cultura popular de massa à alta cultura" (p.94). Argumentam, portanto, que esta mídia "preside um trânsito crucial no desenvolvimento da modernidade: a passagem de uma cultura organizada hierarquicamente, baseada em pontos diferencias de acesso e na distinção estamental dos consumos, para uma cultura distribuída massivamente mediante novas relações entre os mercados, as indústrias e os bens culturais" (p.21). Consideram a televisão "como a zona de máximo contato com a contemporaneidade", cujos efeitos não devem ser valorizados por sua incidência no comportamento explícito dos indivíduos, mas sim sobre os padrões de conhecimento coletivos e a imagem global da sociedade, em uma "rede de interdependência" com outros meios de comunicação. "Não nos dizem o que 
pensar, mas sobre o que pensar". "Não constroem a realidade social, mas traçam para nós uma espécie de mapa onde as posições mais relevantes aparecem mais visivelmente ressaltadas" (p.41). "Reflete uma estética da abundância, inclusive ali onde suas mensagens são recebidas em meio à escassez e ao analfabetismo" ( $p$. 95).

É possível que um dos recursos sedutores da televisão seja, precisamente, esta aparência de ter uma grande abundância de ofertas e, por isso, não parecer impositiva. No entanto, pergunto-me se o que a televisão oferece hoje, mesmo com sua expansão via cabo e "pay per view", não é uma abundância monótona.

Contudo, o ponto que mais me interessa contrastar entre as posições de Piccini e Brunner-Catalán é a concordância em que a televisão tem uma função basicamente reprodutora da ordem social. A diferença destes últimos, ou seja, dos autores chilenos é que para eles "toda cultura, na verdade, é uma certa ordem, um conjunto público, padronizado de valores comunitários que permitem intermediar a experiência individual" (p. 94). À concepção da sociologia da qual eles falam, "o caos e as transformações só interessam quando vê-se surgir deles a ordem" (p. 98). Conseqüentemente, seu argumento mais pungente - oposto tanto às "minorias morais" conservadoras que estimulam a censura na televisão, quanto das elites intelectuais incapazes de apreciar o "caráter historicamente revolucionário deste meio" (p. 94) - subordina os juízos sobre a comunicação massificada a uma política entendida como manutenção do consenso, da ordem e da governabilidade.

Penso que algumas experiências da televisão pública (PBS, BBC, Canais 11 e 12 no México, o canal franco-alemão Arte e outros) permitem imaginar que não é um destino fatal da TV excluir a inovação estética e a mudança social. A interdependência com outros meios citada por Brunner e Catalán, comprovada em muitos estudos de recepção, convida a pensar sobre as formas possíveis em que a televisão poderia articular-se com modalidades críticas de comunicação mais presentes na imprensa e no rádio.

Quero dizer, para finalizar este texto que essas oportunidades dos meios não serem meros reprodutores da ordem, de uma "normalidade" tão insatisfatória, depende do lugar que as políticas culturais confiram dentro da comunicação midiática aos setores sociais não interessados centralmente nos aspectos mercantis da cultura audiovisual: a escola, os organismos culturais, ecológicos, artísticos, de direitos humanos. Talvez, então, os meios de comunicação conheçam verdadeiramente a abundância possível nas nossas sociedades globalizadas e multiculturais. Teremos, não apenas cidadãos imaginados pelos meios, mas imaginados pelos cidadãos. Talvez, assim, os meios compartilhem esta abundância com aqueles que Ihes são tão fiéis a partir de culturas da privação. 


\section{BIBLIOGRAFIA}

BRUNNER, José Joaquín \& CATALÁN, Carlos. (1995) Televisión, libertad, mercado y moral, Chile, Editorial Los Andes.

CAMPRA, Rosalba. (1994) La ciudad en el discurso literario. SYC, Buenos Aires, $n^{\circ} 5$, mayo.

CASTELLS, Manuel. (1983) La ciudad y las masas, Madrid, Alianza.

(1995) La ciudad informacional. Tecnologias de la información, reestructuración economica y el proceso urbano regional, Madrid, Alianza Editorial.

DíAZ, Miguel Angel Agilar. (1996) Espacio Público y prensa urbana en la ciudad de México, Revista Perfiles Latinoamericanos, Año 5, n9, Flacso-México.

GARCÍA CANCLINI, Néstor \& PICCINI, Mabel. (1993) Culturas de la ciudad de México: símbolos colectivos y usos del espacio urbano. In: CANCLINI, Néstor García (org.) El consumo cultural en México, México, Consejo Nacional para la Cultura y las Artes, Seminário de Estúdios de la Cultura.

GARCÍA CANCLINI, Nestor. (1995) Consumidores y ciudadanos. Conflictos multiculturales de la globalización, México, Grijalbo.

CASTELLANOS, Alejandro \& ROSAS MANTECÓN, Ana. (1996) La ciudad de los viajeros, México, Grijalbo-UAM.

GIGLIA, Angela \& WINOCUR, Rosalía. (1996) La participación en la radio: entre inquietudes ciudadanas y estratégias midiáticas. Revista Perfiles Latinoamericanos, Año 5, n9, Flacso-México.

KEANE, John. (1995) Structural Transformations of the Public Sphere. The Communication Review, vol.1, $\mathrm{n}^{\circ} 1$, Gordon and Breach Publishers.

MARTíN BARBERO, Jesús. (1987) De los médios a las mediaciones. Comunicación, cultura y hegemonia, México, G. Gili.

Caracas, Fundarte, Ateneo de Caracas.

(1994) Mediaciones urbanas y nuevos escenarios de comunicación.

PICCINI, Mabel. (1996) Acerca de la comunicación en las grandes ciudades. Revista Perfiles Latinoamericanos, Año 5, n9 , Flacso-México.

SARLO, Beatriz. (1994) Escenas de la vida posmoderna. Intelectuales, arte y videocultura en la Argentina, Buenos Aires, Ariel.

Aires, Ariel.

. (1996) Instantâneas. Médios, Ciudades y costumbres en el fin de siglo, Buenos

SILVA, Armando. (1996) Nuevas fantasías en las noticias de televisión. Revista Perfiles Latinoamericanos, Año 5, nº , Flacso-México.

Tradução do original em espanhol "Ciudades y ciudadanos imaginados por los medios". Perfiles Latinoamericanos. Año 5, nº. Flacso-México. 1996.

Tradução e publicação autorizadas pelo autor, em julho de 1999.

Tradução de Javier Esteban Cencig 